\title{
Application of ferroelectrics to create electroluminescent indicators of temperature
}

\author{
V.G. Boyko, N.S. Zayats \\ V. Lashkaryov Institute of Semiconductor Physics, NAS of Ukraine, \\ 45, prospect Nauky,03028 Kyiv, phone: (38044) 525-62-81,e-mail: zayats@isp.kiev.ua
}

\begin{abstract}
In this article, temperature dependences of brightness of thin film electroluminescent emitters (TFELE) based on metal-dielectric-semiconductor-metal (MDSM) structures with ceramic ferroelectric dielectric have been considered. Their comparable analysis with the temperature dependence of dielectric themself has been made. Literature data concerning this question have been briefly discussed. The conclusion about the possibility to use ferroelectrics (ceramics based on $\mathrm{BaTiO}_{3}, \mathrm{AlN}$, $\mathrm{LiNbO}_{3}$ ) with a pronounced thermal dependence of capacitance characteristics to produce the temperature light indicators has been made. The design of a new temperature sensor can be realized in several ways. For example, in the form of the scales with a moving luminous column or separate lighting dots, depending on how clearly Curie peaks are observed on the temperature curves of dielectric permittivity.
\end{abstract}

Keywords: thin film electroluminescent structure (TFELS), ferroelectric, dielectric permittivity, Curie point, temperature.

Manuscript received 06.02.12; revised version received 20.03.12; accepted for publication 27.03.12; published online 15.05.12.

\section{Introduction}

The interest to development in the area of making the thin film electroluminescent structures (TFELS), as it is well known, is mainly related with the possibility of their using in the miscellaneous type of information displays. However, competition on the part of cathode ray tubes, liquid-crystal displays, light-emitting diodes and the other type screens [1], as well as specific lacks of TFELS limit their mass consumption.

The analysis of necessary demands for TFELS shows that these structures find and can find using not only in screens, but also in more simple devices, namely: light scales, point sources of light, signal indicators [1]. In particular, the authors of this paper propose light indicators of the temperature. So, in this context, it is very interesting to consider temperature characteristics of EL emitters.

When studying temperature effects in thin-film emitters of the type MDSDM (metal-dielectricsemiconductor-dielectric-metal) under excitation by ac current, it was ascertained that characteristics of these structures change to higher or lower degree with changing the temperature $T$, depending on material of dielectric and semiconductor layers as well as methods of their deposition. In particular, for the film system $\mathrm{Y}_{2} \mathrm{O}_{3}-\mathrm{ZnS}-\mathrm{Y}_{2} \mathrm{O}_{3}$ brightness is a monotonous decreasing function of temperature [2].

Moreover, in the structure $\mathrm{Al}_{2} \mathrm{O}_{3}-\mathrm{ZnS}-\mathrm{SiO}_{2}$ an essential temperature shift of the electroluminescence threshold with a simultaneous change in the capacitance of dielectric layers was observed. These phenomena were explained by temperature changes of electric characteristics in $\mathrm{SiO}_{2}$ layer [3].

So, in each specific case it is necessary to investigate the temperature dependences of electroluminescence characteristics of whole TFELS and electric parameters of its component parts.

The importance of these studies is conditioned by the fact that changing the temperature can result in redistribution of applied voltages between luminescent and dielectric layers, because of the temperature change 
in electric parameters of the latter that will influence the electroluminescence excitation process. It should be supposed that this effect in TFELS with dielectric layers from ferroelectrics, which have high values of the dielectric permittivity and their clearly expressed dependence on temperature, is particularly pronounced.

So, in this work performed in a wide interval of temperatures researched were electric parameters of the ferroelectric substrates on which TFELS were formed (in our case $\mathrm{ZnS}: \mathrm{Mn}$ ), and relationship of these parameters with light-technical characteristics of this structure as a whole was established. As a result of analysis of the obtained data, there was offered the possibility to make a new light type temperature sensor.

\section{Experimental}

The investigated structures were made using the lowfrequency ferroelectric ceramics base on barium titanate $\left(\mathrm{BaTiO}_{3}\right)$ as dielectric layers. The ceramic substrates of 0.3 and $0.35 \mathrm{~mm}$ thick had high dielectric constants 11000 and 5000, respectively. The composition and ceramic marks, applicable as substrates for fabrication of EL emitters, and their basic characteristics are summarized in Table.

The polished ceramic substrates (disks about $6 \mathrm{~mm}$ in diameter and $0.3 \ldots 0.35 \mathrm{~mm}$ thick) were manufactured on the capacitor plant "Kation".

The electrical properties were measured in the metal-dielectric-metal (MDM) configuration with the Al electrodes (with the diameter close to $5 \mathrm{~mm}$ and thickness $1.5 \mu \mathrm{m}$ ) were thermally deposited in vacuum on both surfaces of the ceramic disks at the substrate temperature $150{ }^{\circ} \mathrm{C}$.

The electroluminescence properties were measured in the metal-dielectric-semiconductor-metal (MDSM) geometry with the $\mathrm{ZnS}: \mathrm{Mn}$ films ( $5 \mathrm{~mm}$ in diameter and $0.6 \mu \mathrm{m}$ in thickness) deposited directly on heated to $150{ }^{\circ} \mathrm{C}$ ceramic substrates by the method of electronbeam evaporation from $\mathrm{ZnS}: 1 \% \mathrm{MnS}$ pellets without any post-heat-treatment after deposition. As upper transparent electrodes, we used $\mathrm{Au}$ semitransparent layers (diameter $5 \mathrm{~mm}$ ) deposited by means of thermal vacuum evaporation.

The capacitance and luminescence intensity were measured with a digital LCR meter and photoamplifier, respectively, by applying of $1-\mathrm{kHz}$ sinusoidal excitation voltages to the structures. All the temperature measurements within the range $100 \ldots 400 \mathrm{~K}$ were carried out using an optical cryostat with a heater.

\section{Results and discussion}

Presented in Fig. 1 are the temperature dependences of EL intensity in the emitters with substrates from ceramics of different marks. Fig. 2 shows dependences of the capacitance (or dielectric permittivity) of these substrates on temperature.

From comparison of the data in Figs. 1 and 2, it is seen that the temperature behavior of EL intensity and dielectric permittivity correlates one to another and differs by the maximum position of curves for different types of these ceramics. I.e. in our case, when bulk dielectric with the abrupt temperature dependence of electric characteristics was used, the change of the luminescence intensity in radiating elements with the change of temperature can be planned for corresponding substrates in accordance with their temperature characteristics.

The electroluminescent structures are threshold devices, and the light emission begins when a value of the applied voltage reaches its threshold value $\left(U_{t h}\right)$.

Table. Typical properties of ferroelectric ceramics.

\begin{tabular}{|c|c|c|c|c|c|c|}
\hline $\begin{array}{l}\text { Ceramic } \\
\text { marks }\end{array}$ & \multicolumn{2}{|c|}{$\begin{array}{l}\text { Composition, } \\
\text { wt. } \%\end{array}$} & $\begin{array}{l}\text { Dielectric } \\
\text { loss tangent } \\
\text { at } 1 \mathrm{kHz} \text {, } \\
\operatorname{tg}(\delta) \times 10^{-4}\end{array}$ & $\begin{array}{c}\text { Operation } \\
\text { temperature } \\
\text { interval, } \\
{ }^{\circ} \mathrm{C}\end{array}$ & $\begin{array}{l}\text { Curie } \\
\text { point, } \\
{ }^{\circ} \mathrm{C}\end{array}$ & $\begin{array}{c}\text { Dielectric } \\
\text { permittivity } \\
\text { at } 20 \pm 5^{\circ} \mathrm{C}, \\
\varepsilon\end{array}$ \\
\hline $\mathrm{T}-4500$ & $\begin{array}{l}\mathrm{BaTiO}_{3} \\
\mathrm{CaZrO} \\
\mathrm{Kaolin} \\
\mathrm{ZnO} \\
\mathrm{MnCO}_{3} \\
\mathrm{MgTiO} \\
\mathrm{SrCO}_{3}\end{array}$ & $\begin{array}{r}87.65 \\
10.75 \\
1.20 \\
0.30 \\
0.10 \\
0.2-3.4 \\
\text { over } 100 \\
1.0 \\
\text { over } 100\end{array}$ & 250 & $-40 \ldots+85$ & - & 4500 \\
\hline $\mathrm{T}-11000$ & $\begin{array}{l}\mathrm{BaTiO}_{3} \\
\mathrm{CaSnO}_{3} \\
\mathrm{Kaolin} \\
\mathrm{MnCO}_{3} \\
\mathrm{Nb}_{2} \mathrm{O}_{5}\end{array}$ & $\begin{array}{r}88.84 \\
10.81 \\
0.25 \\
0.1 \\
0.5 \\
\text { over } 100\end{array}$ & 250 & $-40 \ldots+85$ & $\begin{array}{c}+10 \ldots+4 \\
0\end{array}$ & 10000 \\
\hline
\end{tabular}


From this time point, the device begins to radiate light in the manner of pulses during each half-period of the alternating voltage, since in absence of the luminescence TFEL-element can be considered as a capacitor. It is easy to show that under $\operatorname{tg}(\delta)<<1$ (it is valid near the threshold voltages, i.e. under low levels of the brightness, when impedances of $\mathrm{D}$ and $\mathrm{S}$ layers are basically defined by their capacitances) $U_{t h}$ (i.e., the minimum voltage applied to the structure under which all the operation area of a sample begins to evenly shine) is related with the threshold field value $E_{a}$ in the luminescent layer by the following equation:

$U_{t h}=\left(d_{a}+\varepsilon_{a} d_{D} / \varepsilon_{D}\right) E_{a}$,

where $E_{a}$ is the threshold electric field in the luminescent layer, $d_{a}$ and $d_{D}$ are the thicknesses of the luminescent and dielectric layers, respectively, $\varepsilon_{a}-$ dielectric permittivity of the luminescent layer, $\varepsilon_{D}-$ dielectric permittivity of ceramics [4].

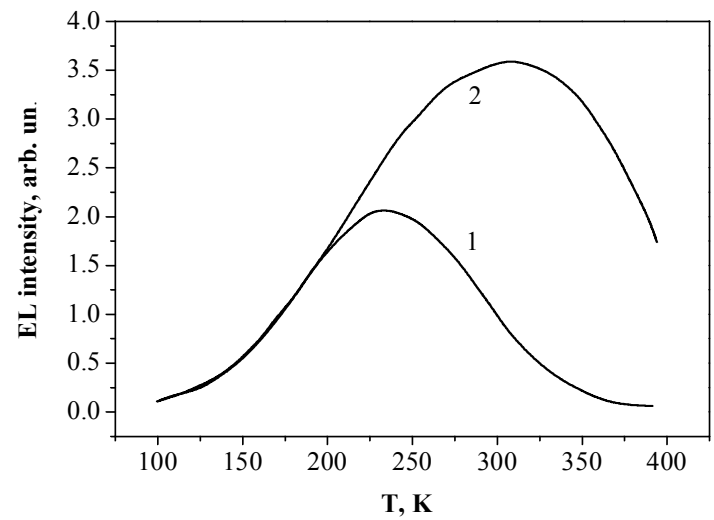

Fig. 1. Temperature dependence of EL-intensity of the emitters on ceramic substrates of T-4500 (1) and T$11000(2)$.

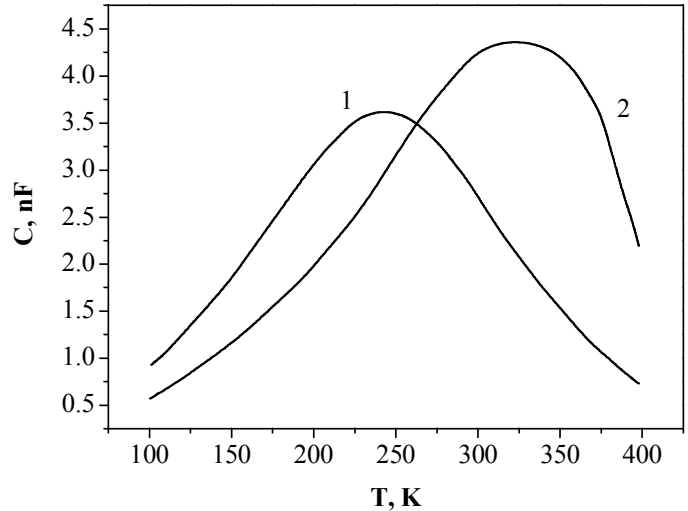

Fig. 2. Temperature dependence of the dielectric capacitance of T-4500 (1) and T-11000 (2).
Typical for the ferroelectric polar phase (i.e. the temperature range, where $T<T_{\mathrm{C}}-$ a Curie temperature) Curie-Weiss's law describing a temperature dependence of the dielectric permittivity in the crystals looks as follows:

$\varepsilon=C_{\mathrm{C}} / 2\left(T_{\mathrm{C}}-T\right)$,

where $C_{\mathrm{C}}$ is the Curie-Weiss constant $[5,6]$. Substituting (2) into (1), one can obtain the expression describing the dependence of the lighting threshold of the electroluminescence on temperature in TFELS:

$U_{t h}=\left[d_{a}+2 \varepsilon_{a} d_{D}\left(T_{\mathrm{C}}-T\right) / C_{\mathrm{C}}\right] E_{a}$.

Perceiving from the expression (3), one can estimate the sensitivity of this structure with the $\mathrm{BaTiO}_{3}$ crystal. The change in $U_{t h}$ with varying the temperature by one degree will look as:

$\Delta U_{t h}=2 \varepsilon_{a} d_{D} E_{a} / C_{\mathrm{C}}$.

For $\mathrm{ZnS} \varepsilon_{a}=9, E_{a}=2 \times 10^{6} \mathrm{~V} / \mathrm{cm}$ [2], $C_{\mathrm{C}}=$ $1.2 \times 10^{5} \mathrm{~K}$ for $\mathrm{BaTiO}_{3}$ [9] and $d_{D}=3 \times 10^{-2} \mathrm{~cm}$, which yields $\Delta U_{t h}=0.9 \mathrm{~V} /$ degree. It is seen from the expression (3) that changing the values of the Curie point for substrates in such a manner that the value of $T_{\mathrm{C}}-T$ remains constant, the value of $U_{t h}$ will remain constant, too. I.e. Eq. (3) can be a basic characteristic for practical realization of the proposed thermometer. In this relation, mixed crystals can be of considerable interest [6]. The mixed crystals can be of a ferroelectric type and not of this one. Their Curie point can be shifted in wide interval of temperatures.

If barium titanate is accomplished with the ferroelectric possessing a Curie point higher than $120{ }^{\circ} \mathrm{C}$ ( $\mathrm{BaTiO}_{3}$ Curie point), and the row of solid solutions is formed between compounds, then the Curie point of the latter lies above $\mathrm{BaTiO}_{3}$ Curie point. For instance, the compounds raising the Curie point are $\mathrm{PbTiO}_{3}, \mathrm{PbZrO}_{3}$ and others. The compounds $\mathrm{BaSnO}_{3}, \mathrm{BaZrO}_{3}, \mathrm{SrTiO}_{3}$ and others form with $\mathrm{BaTiO}_{3}$ the continuous row of solid solutions which lowers its Curie point. Position of the Curie point is shown in Fig. 3 for the binary system $\mathrm{BaTiO}_{3}-\mathrm{SrTiO}_{3}$.

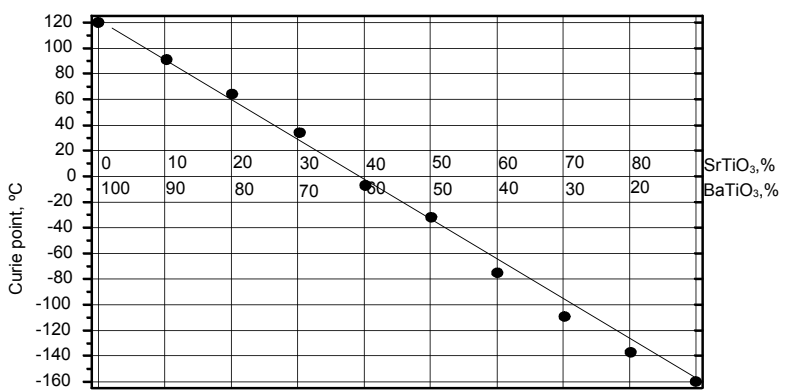


The linear dependence for the Curie point on composition overlaps the temperature range from $160{ }^{\circ} \mathrm{C}$ up to $+120^{\circ} \mathrm{C}$. Starting from the expression (3) and Fig. 3 and taking into account that the dielectric permittivity of AlN increases from 9 up to 100 at frequencies $100 \ldots 1000 \mathrm{~Hz}$ within the temperature range $20{ }^{\circ} \mathrm{C} \ldots 500{ }^{\circ} \mathrm{C}[7,8]$, and $\mathrm{LiNbO}_{3}$ ferroelectric has the Curie point $1483 \mathrm{~K}$ [9], one can expect that the most expedient is to produce temperature EL indicators with the accuracy $10{ }^{\circ} \mathrm{C}$, which can be used within the range $-160{ }^{\circ} \mathrm{C}$ to $+500{ }^{\circ} \mathrm{C}$. The upper temperature limit of EL indicators can be set by temperature conditions of excitation and quenching their luminosity [10] and also by the Debye temperature of materials. Design of the thermometer can be realized in several ways. For instance, in the manner of the scales with a moving luminous column or separate lighting points, depending on how clearly Curie peaks are observed on the temperature curves of dielectric constants.

\section{Conclusions}

In conclusion, it seems necessary to note that the basic physical and technical feature of light temperature indicators is that the dielectric layer is not a passive element in the classical sense (an insulator), but an active functional element (a ferroelectric material with clearly pronounced temperature dependence of the dielectric permittivity $\varepsilon=f(T)$ ) in the electroluminescent structure, which effectively operates its luminescent properties in a wide range of change of temperatures.

The considered indicators can be excited by the network voltage $220 \mathrm{~V}$ at the frequency $50 \mathrm{~Hz}$. At these excitation conditions the brightness about $80 \mathrm{Cd} / \mathrm{m}^{2}$ was reached. The main difficulty in fabrication of these structures is a very complicated sintering technology of ferroelectric ceramics with crystalline and polycrystalline phases.

\section{References}

1. I.K. Vereschagin, B.A. Kovalev, L.A. Kosyachenko, S.M. Kokin, Electroluminescent Light Source. Energoatomizdat, Moscow, 1990 (in Russian).
2. R. Mach, G.O. Muller, Physical concepts of high-field, thin-film devices electroluminescent // Phys. Status Solidi, 69(a), No.11, p. 11-66 (1982).

3. S.I. Balyasnaya, L.I. Veligura, N.A. Vlasenko, V.S. Khomchenko, On the nature of the temperature dependence of the characteristics of thin-film electroluminescent MDPDMstructures based on $\mathrm{ZnS}: \mathrm{TbF}_{3} / /$ Optoelektronika $i$ poluprovodnikovaia tekhnika, 18, p. 81-85 (1990), in Russian.

4. N.M. Parfenov, S.M. Kokin, B.G. Bekker, I.E. Ostriy, A.V. Lipoveckiy, A.D. Chromov, The influence of dielectrics on the parameters of thin-film electroluminescent structures // Izvestiya vuzov. Fizika, No. 4, p. 119-120 (1985), in Russian.

5. Yu.M. Poplavko, Physics of Dielectrics. Vyshcha shkola, Kiev, 1980 (in Russian).

6. A. Andrianov, N.P. Bogorodickiy, Yu.V. Korickiy, Handbook on Electrotechnical Materials. Gosenergoizdat, Moscow-Leningrad, vol. II, 1960 (in Russian).

7. T.J. Kosolapova, T.B. Andreeva, T.S. Bartnitskaya et al., Nonmetallic Refractory Compounds. Metallurgiya, Moscow, 1985 (in Russian).

8. V.G. Boyko, M.S. Zayats, S.M. Zayats et al., Electrophysical properties of AlN obtained by high-frequency reactive magnetron sputtering // Physics and technology of thin films and nanosystems (ICPTTFN-XIII): XIII International Materials Conference, 16-21 May 2011, Ivano-Frankivsk, Ukraine, V.1, p. 157 (2011).

9. V.G. Kolesnikov, Electronics, in: Encyclopedic Dictionary. Sovetskaya entsiklopediya, Moscow, 1991 (in Russian).

10. I.K. Vereshchagin, Electroluminescence of Crystals. Nauka, Moscow, 1974 (in Russian). 